\title{
Significações dos estudantes sobre o currículo cultural da Educação Física
}

Jorge Luiz de Oliveira Júnior ${ }^{a, b *}$, Marcos Garcia Neira ${ }^{b, c}(\mathbb{D}$

Palavras Chave:

Curriculum;

Culture;

Physical Education;

Students.

\section{Keywords:}

Currículo;

Cultura;

Educação Física;

Estudantes.

Palavras Chave:

Curriculum;

Cultura;

Educación Física;

Estudiantes.

\begin{abstract}
RESUMO
O presente estudo investigou as significações expressas pelos estudantes sobre as aulas de Educação Física culturalmente orientadas em uma escola municipal paulistana. Os dados analisados sugerem que a proposta cumpre com suas premissas e, em alguns casos, extrapola as expectativas iniciais ao constatar-se que os estudantes se sentem encorajados a desconstruir discursos preconceituosos sobre as práticas corporais ou seus representantes, quando postos em circulação.
\end{abstract}

\begin{abstract}
The present study investigated the meanings expressed by the students about the culturally oriented classes of Physical Education in a municipal school in São Paulo. The data analyzed suggest that the proposal fulfills its premises and, in some cases, exceeds initial expectations when it is found that students are encouraged to deconstruct prejudiced discourses about corporal practices or their representatives, when put into circulation.
\end{abstract}

\section{RESUMEN}

El presente estúdio investigo las significaciones expresadas por los estudiantes sobre las clases de Educación Física culturalmente orientadas en una escuela municipal paulistana. Los datos analizados sugieren que la propuesta cumple con sus premisas y, en algunos casos, supera las expectativas iniciales cuando se descubre que se alienta a los estudiantes a deconstruir discursos prejuiciosos sobre prácticas corporales o sus representantes, cuando se ponen en circulación.

\footnotetext{
a Secretaria Municipal de Educação de São Paulo, São Paulo, SP, Brasil.

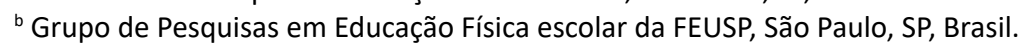

' Faculdade de Educação da Universidade de São Paulo, São Paulo, SP, Brasil.
}

\section{*Autor correspondente:}

Jorge Luiz de Oliveira Júnior

E-mail: jorgejref@yahoo.com.br 


\section{INTRODUÇÃO}

A recente disseminação das teorias pós-críticas ${ }^{1}$ educacionais têm influenciado os estudos curriculares (PARAÍsO, 2004) e o fazer pedagógico de professores da Educação Básica pelo país afora. Esses referenciais contagiaram a Educação Física a ponto de inspirar a experimentação de uma nova proposta, o chamado currículo cultural da Educação Física.

Em linhas gerais, o currículo cultural propõe a tematização das práticas corporais, problematizando a sua ocorrência social e desconstruindo ${ }^{2}$ os significados que Ihes são atribuídos, a fim de aprofundar e ampliar os conhecimentos acessados pelos estudantes e estabelecer um diálogo profícuo com as diferenças.

A crescente adesão de docentes à proposta despertou o interesse de alguns pesquisadores: Neira (2011) investigou a produção discursiva de professores que colocam em ação o currículo cultural da Educação Física; Escudero (2011) analisou as práticas avaliativas na perspectiva cultural do componente; Santos (2016) estudou como educadores que atuam nessa vertente tematizam as práticas corporais e problematizam as representações dos estudantes; Müller (2016) investigou a influência dos registros sobre a reorientação da sua prática pedagógica; Bonetto (2016) analisou como os professores que atuam com o currículo cultural da Educação Física constroem suas práticas pedagógicas com base no conceito de escritacurrículo; e Nunes (2018) averiguou como os docentes tratam as diferenças nas aulas de Educação Física culturalmente orientadas.

As pesquisas citadas se atentaram a ouvir, observar e acompanhar os professores que colocam em ação a proposta, mas nada foi dito do que pensam os estudantes. Nessa sintonia, Neira (2016a) investigou os efeitos do currículo cultural da Educação Física na constituição das identidades dos estudantes de uma escola municipal de São Paulo e Neves (2018) analisou as mudanças dos sujeitos nos modos de significar as práticas corporais e seus representantes. Enquanto isso, o presente estudo percorreu outro caminho ao pesquisar as significações que o alunado atribui às aulas de Educação Física culturalmente orientadas.

\footnotetext{
${ }^{1}$ Geradas em meio aos movimentos que questionaram os desígnios culturais, políticos e econômicos da Modernidade, as teorias pós-críticas ampliam as análises realizadas pelas teorias críticas quando indagam as pretensões totalizantes das grandes narrativas, do sujeito autônomo e centrado do projeto moderno e os processos de dominação e poder baseados em relações sociais pautadas na divisão de classe (SILVA, 2011). ${ }^{2}$ No entender de Costa (2010), desconstruir não é destruir, desconstruir requer procedimentos de análise do discurso, "que pretendem mostrar as operações, os processos que estão implicados na formulação de narrativas tomadas como verdades, em geral, tidas como universais e inquestionáveis" (p. 140). A desconstrução põe a nu as relações entre discursos e poder.
}

Partindo do pressuposto que o currículo cultural da Educação Física pretende posicionar os estudantes como leitores e produtores das práticas corporais, visando à compreensão dos modos como são produzidas em meio às relações de poder, pareceu relevante investigar os significados que os sujeitos atribuem a esse processo.

Importa lembrar que significar é fazer valer significados particulares, próprios de um grupo cultural sobre os significados de outros grupos culturais. De acordo com Silva (2010), as práticas de significação não podem ser pensadas sem as relações de poder, pois é precisamente a operação do poder que transforma o campo produtivo dos significados. Por estarem ligadas a processos discursivos, as práticas de significação assumem um caráter produtivo, num processo constante de suspensão e modificação.

\section{CURRÍCULO CULTURAL DA EDUCAÇÃO FÍSICA}

Na acepção de Silva (2011), o currículo não pode ser visto como um empreendimento que agrega procedimentos, técnicas, métodos e conteúdos formais a serem ensinados pelo professor em sala de aula. A partir das chamadas teorias pós-críticas, currículo passa a ser concebido como tudo aquilo que forma as identidades dos sujeitos escolares. Enquanto artefato cultural profundamente implicado em relações de poder, não pode ser tratado como dispositivo neutro de transmissão de conhecimentos. O que é ensinado e o como se ensina assumem um caráter parcial e arbitrário, produzindo efeitos inesperados nos discentes e docentes.

O currículo pós-crítico se opõe ao tecnicismo educacional na medida em que invoca todo e qualquer conhecimento como digno de constituir a experiência escolar (CORAZZA, 2001). Os saberes populares, urbanos, rurais, periféricos, indígenas, místicos etc. possuem o mesmo grau de importância que os saberes científicos, pois são compreendidos como produtos do processo de significação influenciados por vetores de força. Assim, os conhecimentos pautados pela ciência moderna são tidos como mais uma forma, entre outras, de compreender o mundo.

Pensando no ensino da Educação Física, um traço distintivo dessa perspectiva curricular é a análise do modo como se instituem os marcadores sociais da diferença (classe, raça, religião, etnia, gênero etc.) que impregnam as práticas corporais (NUNES, 2018). Para além de reconhecer e propor diálogos entre grupos culturais distintos, um currículo pós-crítico preocupa-se não só com os efeitos dos discursos na constituição dos sujeitos, mas, principalmente, como esses discursos 
são produzidos, postos em circulação e a quem isso favorece.

Neira e Nunes (2018) relatam que um grupo de professores e professoras de Educação Física que atuavam na Educação Básica no princípio deste século, insatisfeito com as propostas existentes, deixou-se influenciar pelas teorias pós-críticas e passaram a realizar experimentos pedagógicos. Os resultados alcançados e os registros dessas experiências foram transformados em objetos de estudo, tornando possível a produção de uma teoria curricular denominada cultural, culturalmente orientada ou currículo cultural.

O currículo cultural da Educação Física nutre-se nos pressupostos teóricos e políticos dos Estudos Culturais na sua vertente pós-estruturalista, que concebem a cultura como prática de significação e ensinam que, do ponto de vista da valoração, não há distinção entre a cultura de elite e de massa, cultura midiática e popular (NELSON; TREICHLER; GROSSBERG, 2009). Todas as culturas são importantes e necessitam ser debatidas em pé de igualdade. Entretanto, no jogo de forças políticas, a proposta em questão posiciona-se favoravelmente aos grupos em desvantagem nas relações de poder como forma de serem reconhecidos na teia social.

O currículo cultural da Educação Física volta-se para a compreensão da ocorrência social das práticas corporais, estimulando a sua reelaboração de acordo com as características dos estudantes e as condições da escola. Ao tematizar a brincadeira, dança, luta, esporte ou ginástica tenciona intervir a favor da construção de significados mais democráticos, com vistas a atuar em defesa do direito das pessoas que participam dessas práticas corporais a expressarem o próprio modo de se fazerem representar (NEIRA, 2018).

Segundo o autor, os docentes que afirmam colocar em ação o currículo cultural da Educação Física são influenciados por determinados princípios éticopolíticos, tanto na definição dos temas quanto na organização e desenvolvimento das atividades de ensino. São eles: articulação com o projeto pedagógico da escola, reconhecimento da cultura corporal da comunidade, justiça curricular, rejeição ao daltonismo cultural, descolonização do currículo e ancoragem social dos conhecimentos. Sem configurar etapas ordenadas previamente, os procedimentos didáticos abarcam situações de mapeamento, vivência, leitura da prática corporal, ressignificação, aprofundamento, ampliação, registro e avaliação.

Neves (2018) percebeu que a perspectiva cultural da Educação Física assume também uma postura de desconstrução das representações a respeito das práticas corporais e seus participantes. No decorrer da tematização, os estudantes vivenciam as práticas corporais, analisam os modos de sua ocorrência, os contextos históricos que proporcionaram o seu surgimento, as incidências nos processos de significação e representação, as intenções políticas de seus representantes, entre tantos outros aspectos (SANTOS, 2016).

Por assumir posturas que escapam à lógica homogeneizante ${ }^{3}$ que engessa o ensino da Educação Física, o currículo cultural prioriza mecanismos democráticos para a definição dos temas e das situações didáticas. Desse modo,

[...] não compactua com a ideia de fase apropriada, maturidade adequada ou prontidão. Recusa-se, por exemplo, a tematizar brincadeiras somente para as crianças pequenas por causa da idade, alegando serem imaturas, enquanto que os jovens não teriam interesse nelas. Desde que se leve em consideração o histórico cultural de cada grupo, todas e quaisquer práticas corporais podem ser investigadas em quaisquer etapas da Educação Básica (OLIVEIRA JUNIOR; NEIRA, 2017, p. 42).

Durante a sua empreitada diária, o currículo cultural cria condições para a valorização do direito às diferenças. Silva (2013) explica que as diferenças são produzidas discursivamente em meio às relações de poder, ou seja, decorrem de práticas de significação. As diferenças não são entidades pré-existentes, essenciais, únicas. Pelo contrário, são constantemente produzidas, portanto, efeitos do processo de significação.

A diferença precisa ser compreendida como uma questão política, como um processo de produção permanente que interessa a alguém. Não se trata de tolerar, respeitar e aceitar a diferença. O que importa é explicá-la, não como ela 'é', mas sim como 'está sendo' produzida, buscando destrinchar as forças atuantes e as formas de operação do poder nesse processo (SILVA, 2013).

O currículo cultural da Educação Física busca analisar como as diferenças alusivas às práticas corporais são produzidas. Para tanto, os estudantes são convidados a questionarem e transgredirem o pensamento hegemônico e a caminharem em direção ao inexplorado. A ousadia almejada pela Educação Física cultural talvez seja provocar nos estudantes um sentimento questionador além dos muros escolares, convidando-os a agir em diferentes espaços onde discursos preconceituosos que marginalizam grupos e práticas corporais circulam sem interrupções e questionamentos.

Enfim, o currículo cultural da Educação Física, para além de uma maneira de conduzir a prática pedagógica,

\footnotetext{
${ }^{3}$ Por mais que se tenha avançado nas pesquisas sobre Educação Física escolar na área das Linguagens, é possível observar a permanência de influências psicobiológicas que buscam a produção de corpos saudáveis ou habilidosos.
} 
é também uma forma de potencializar a própria existência e a dos outros. Mazzoni (2013) constatou que o professor não escolhe, simplesmente, pensar e trabalhar com os Estudos Culturais, isso decorre da sua trajetória de vida e do conjunto de valores que a norteiam. $O$ docente vive o currículo cultural ao se incomodar com as injustiças do cotidiano ou ao enfrentar o pensamento hegemônico presente nas relações sociais. Para tanto, luta em defesa das significações daqueles grupos desprivilegiados nas relações de poder.

\section{MATERIAIS E MÉTODOS}

O foco da presente pesquisa qualitativa foi analisar como os estudantes ${ }^{4}$ significam as aulas de Educação Física culturalmente orientadas. Adotou-se a etnografia pós-crítica enquanto proposta metodológica, o que incluiu a observação das aulas e outros momentos escolares, realização de entrevistas e análise de documentos.

A etnografia pós-crítica pauta-se nas contribuições das pesquisas pós-críticas em educação (MEYER; PARAÍSO, 2014). Em linhas gerais, essa perspectiva teórico-metodológica abarca a possibilidade de analisar as operações do poder entre os participantes do processo investigativo e de considerar o caráter produtivo da linguagem ao longo da investigação.

Por ser uma pesquisa etnográfica, mantém a "triangulaçãometodológica" (SALOMÃO, 2017, p.23)que pressupõe observação, análise documental e entrevistas, mas se caracteriza por atentar à subjetividade e às estratégias linguísticas de produção de conhecimentos. O etnógrafo pós-crítico permite-se envolver no campo investigativo porque o que lá acontece não está pronto e definido. Klein e Damico (2014) explicam que esse envolvimento faz com que o pesquisador seja surpreendido e transformado pela própria pesquisa, obrigando-o a reformular suas ideias iniciais.

Sob tais pressupostos, mergulhamos no cotidiano de uma escola municipal paulistana nos anos letivos de 2015 e 2016 para observar as aulas de Educação Física culturalmente orientadas do Ensino Fundamental, além dos horários de entrada e saída, troca de aulas e intervalos, onde fosse possível perceber como os estudantes significavam suas experiências com o currículo cultural. As discussões, reivindicações e conversas entre e com eles foram registradas no diário de campo em formato de episódios. Além disso, analisamos documentos referentes às aulas

\footnotetext{
${ }^{4} \mathrm{Em}$ atendimento aos princípios éticos que norteiam a pesquisa em ciências humanas, os estudantes e seus responsáveis assinaram um Termo de Consentimento Livre e Esclarecido. O projeto foi antecipadamente apresentado e aprovado pela direção da unidade escolar.
}

ministradas durante o período de permanência em campo e entrevistamos alguns estudantes.

De posse dos dados, empregamos a análise cultural (WORTMANN, 2002), pois ela atua no sentido de entender como as práticas culturais são vividas e experimentadas pelos sujeitos como um todo. Por estar conectada diretamente ao campo teórico e político dos Estudos Culturais, a análise cultural se compromete a investigar as práticas sociais considerando as relações de poder nesse processo.

\section{SIGNIFICAÇÕES SOBRE O CURRÍCULO CULTURAL DA EDUCAÇÃO FÍSICA}

A análise das anotações no diário de campo e dos registros que documentam o trabalho pedagógico dá a conhecer que os estudantes atribuem significados positivos a alguns dos aspectos que caracterizam a perspectiva cultural da Educação Física, em especial, os princípios ético-políticos que influenciam a definição de temas e organização das atividades, com destaque para o reconhecimento da cultura corporal da comunidade e a ancoragem social dos conhecimentos; e as situações didáticas propostas, neste caso, os momentos de ressignificação das vivências corporais, bem como o aprofundamento e a ampliação.

Isso foi observado na entrevista da aluna Isadora ${ }^{5}$ que destacou o diálogo como algo importante: "Achei legal também porque o professor deu espaço pra gente falar [...]. Aqui a gente tem tempo pra falar, dar ideias. Achei isso bem bacana". Organizar situações em que os estudantes falem e se posicionem sobre as práticas corporais é uma das marcas do currículo cultural da Educação Física. Neira (2016b) destaca que planejar momentos que convidem os estudantes a se posicionarem acerca dos acontecimentos nas aulas, positivando algumas ações ou sugerindo alterações, promove um ambiente propício ao reconhecimento das diferenças.

A prática dialógica durante a tematização leva os estudantes a se sentirem à vontade para comentar sobre as atividades de ensino. A ampliação, aprofundamento e ressignificação dos conhecimentos decorrem da organização e desenvolvimento das atividades de ensino. Para Neira (2016b), as situações didáticas que singularizam a proposta "são fortemente influenciadas pelas condições da escola, trabalho docente e características da prática corporal em foco" (p. 32).

As atividades de ensino observadas consistiram na assistência a vídeos, leitura e análise de textos, notícias, letras de músicas e poemas, vivências da prática corporal tematizada, discussão sobre os registros de aulas anteriores, livros e pesquisas acadêmicas.

${ }^{5}$ Os nomes são fictícios. 
A estudante Patrícia, durante a tematização do sertanejo, reforça essa observação: "a gente dançou, a gente pesquisou, a gente ouviu as músicas, a gente viu os vídeos das pessoas dançando". Ademais, revelou que essas atividades foram determinantes na sua compreensão do sertanejo: "[...] se o professor não tivesse passado esse texto, eu nunca ia saber as diferenças do sertanejo. Sempre ia achar que era a mesma coisa tudo".

A utilização de vídeos foi destacada pelas alunas Gabriella e Greta. Elas explicaram que o recurso ajudou a aprofundar os conhecimentos sobre o tênis de mesa quando se referiram a existência de várias formas de empunhar a raquete, para além do modelo clássico: "[...] quando o professor trouxe o vídeo, mostrou como segurar a raquete, tal, a gente aprende novas maneiras de como fazer na Educação Física. A gente não fica só na mesma coisa"[...] "quanto mais vídeos a gente assiste, mais a gente consegue entender que não existe só uma maneira, que não existe só aqui no Brasil, que existem várias outras formas da gente fazer manobras".

Os posicionamentos dos estudantes mostram que a Educação Física cultural os contagia de tal modo que passam a reconhecer e legitimar os encaminhamentos pedagógicos adotados pela proposta. De certa forma, ousamos afirmar que as significações são ampliadas, ou seja, passam a encarar as aulas de Educação Física como um momento de investigação das práticas corporais em que se recorre a variadas fontes $e$ recursos.

Ficaram nítidas também as significações atribuídas às ocasiões de aprofundamento, ampliação e ressignificação dos conhecimentos sobre as práticas corporais tematizadas. Percebemos isso quando a aluna Tatiane disse que aprendeu "as diferenças do sertanejo, o romântico, o universitário e o raiz [...] os instrumentos, alguns passos também, conhecemos músicas novas e várias outras coisas".

Isso também foi observado na tematização de skate e patins, ocasião em que o aluno Kauan disse ter aprendido "[...] a virar o skate" e o Kevin falou que aprendeu a "[...] andar um pouco de patins e até consegui me equilibrar mais". Coincidindo com os apontamentos de Neves (2018), percebe-se que as crianças e jovens não só aprofundaram e ampliaram seus conhecimentos por meio da leitura de textos e realização de debates, mas também durante as vivências das práticas corporais.

Momentos de ressignificação dos saberes acerca das práticas corporais também foram notados, por exemplo, quando algumas crianças elaboraram novos gestos e coreografias da ginástica rítmica inspiradas no gênero musical funk (EPISÓDIO 12 - 17/03/2016) e quando alguns alunos passaram a se locomover no skate deitados, em duplas, com um skate em cada pé, logo após o convite para experimentarem novas possibilidades de usar o skate (EPISÓDIO 02 11/08/2015).

A ressignificação decorre da produção cultural, ou seja, do esforço que os sujeitos da educação empreendem para reconstruir a vivência das práticas corporais na escola, como também para enxergá-las por outras lentes. O currículo cultural da Educação Física almeja exatamente isso, que os alunos desestabilizem, modifiquem, criem e ressignifiquem as práticas corporais (NEIRA, 2018).

A compreensão das práticas corporais foi potencializada quando representantes foram convidados a compartilhar suas experiências com a turma. Kevin afirmou ter sido importante a visita de uma patinadora, pois "a entrevista, com aquilo que ela falou, deu pra aprender um pouco sobre os patins. Deu pra aprender como mexer e andar".

$E$ isso não se restringiu apenas a pessoas adultas. Crianças e jovens, colegas da mesma turma ou de outras, também contribuíram com as ressignificações dos demais. Na tematização das brincadeiras, as próprias crianças foram responsáveis pelas explicações do seu funcionamento e características. A cada aula, um grupo de estudantes era convidado a apresentar sua brincadeira aos colegas e discutiam sobre possibilidades de adequação e modificação. Kevin e Leonardo enfatizaram essa ação: "[...] Foi melhor a gente explicar, porque a gente sabe um pouco mais. Os adultos não gostam muito das brincadeiras das crianças, não conhecem muito. Então, foi bem legal".

Não há dúvida que o educador é apenas um dos agentes promotores do acesso às práticas corporais disponíveis na sociedade. Contudo, os pontos de vista dos praticantes, sejam eles idosos, adultos, jovens ou crianças precisam ser reconhecidos e incorporados às aulas. De acordo com Neira (2018), isso faz com que outras formas de significar as práticas corporais sejam acessadas e analisadas.

Um aspecto interessante e que contradiz a visão hegemônica ${ }^{6}$ da área foi perceber que os estudantes consideraram variadas formas de participação nas aulas de Educação Física para além da vivência corporal. A leitura de um livro infantil que conta a história de um casal de idosos auxiliou no entendimento da turma

\footnotetext{
${ }^{6}$ Entendemos como "visão hegemônica" aquela que concebe as aulas de Educação Física como espaço exclusivo para a realização de atividades motoras. Nesse sentido, uma proposta que, além das vivências, organiza situações didáticas de leitura, ressignificação, aprofundamento, ampliação e registro, escapa do convencional.
} 
sobre a presença desse segmento populacional no skate (EPISÓDIO 04 - 18/08/2015). Em outra situação, quando dois alunos que não realizavam a vivência do jiu-jítsu desde o início da tematização, orientaram os colegas de turma que lutavam a adotar algumas estratégias de imobilização e finalização (EPISÓDIO 23 $-28 / 06 / 2016$ ).

$O$ docente que coloca em ação o currículo cultural não nega a vivência corporal, nem tampouco a prioriza. Ela abre as portas para que outras formas de participação dos estudantes aconteçam. Quando as vivências são extrapoladas, propicia-se aos estudantes as "condições necessárias para ampliação das próprias leituras das práticas corporais socialmente situadas e de seus praticantes" (NEIRA, 2016b, p. 43).

A análise dos registros no diário de campo indica que os significados atribuídos pelos estudantes levaram o professor a reorganizar as ações didáticas. Isso foi observado quando o Vinícius, por estar defendendo o estudo do futebol americano, argumentou que poderiam fazer o mesmo que foi feito no ano anterior com o parkour. Segundo ele, deveriam estudar porque as pessoas acham que o futebol americano é violento, além de estudar também as táticas, regras do jogo, nomes dos movimentos e que também poderiam assistir vídeos para aprender sobre esse esporte. Após colocar as sugestões do estudante em debate, a turma defendeu que não só o tema fosse abordado, como também, o formato proposto. (EPISÓDIO 25 - 28/07/2016). Metodologicamente falando, observa-se ao que Bonetto (2016), recuperando as ideias de Corazza (2001), denominou artistagem, didática-artista ou artistada.

O episódio acima evidencia a importância de se atentar aos acontecimentos das aulas, principalmente às respostas dos alunos às atividades, pois é a partir da leitura que o docente faz daquilo que acontece que serão definidos os caminhos posteriores (MÜLLER, 2016).

Por meio da construção de um clima favorável ao diálogo de opiniões e circulação de diferentes significados acerca das práticas corporais, o currículo cultural da Educação Física encoraja as crianças e jovens a desconstruírem os discursos preconceituosos que envolvem as brincadeiras, danças, lutas, esportes e ginásticas ou seus praticantes. Isso foi observado quando um grupo de meninas discordou energicamente da ideia sugerida pelos meninos da turma que o tempo de vivência do futebol delas fosse menor, relembrando-o que desde pequenas as meninas são tratadas como inferiores e que não estariam dispostas a continuar dessa forma (EPISÓDIO 24 - 29/06/2016) e quando o aluno
Daniel se posicionou contra um argumento proferido pela sua mãe de que a prática do skate era coisa de maloqueiro. Repetindo os discursos acessados nas aulas, contou-lhe que os skatistas se vestem com roupas largas para facilitar os movimentos e, na falta de espaços específicos para a prática, usam os ambientes públicos (EPISÓDIO 06 - 16/09/2015). Corroborando o posicionamento de Costa (2010), constata-se que a desconstrução implica desvelar os processos narrativos tidos como verdades inquestionáveis com o intuito de elucidar as etapas e as forças que atuaram na montagem dos discursos.

Consideramos essas situações como possíveis efeitos das tematizações. O mesmo pode ser dito de outro momento, quando Estela, ao realizar uma atividade escrita sobre o futsal e futebol, relatou que o futebol é mais reconhecido que o futsal em nosso país, porque desde pequenos somos induzidos a gostar do esporte por muitos fatores: temos que ter um time para torcer, na televisão só passa futebol, nossos amigos só falam de jogos de futebol etc., e que isso são coisas construídas ao longo do tempo pelas pessoas (EPISÓDIO 22 - 23/06/2016).

As formas como os estudantes significam a proposta não param por aqui, haja vista a condição de autoria curricular percebida em diversas passagens: o aluno Thiago, que era novo na escola, se espantou ao ver pipas na sala de materiais de Educação Física e seu colega de turma, achando aquilo corriqueiro, prontamente respondeu que já havia estudado a pipa nas aulas (EPISÓDIO 01 - 04/08/2015); a Raiane retomou as discussões engendradas ao longo da tematização da ginástica rítmica para argumentar em defesa do reconhecimento feminino nas práticas corporais (EPISÓDIO 27 - 18/08/2016); e um grupo de meninos considerados habilidosos no futebol foi ferozmente rebatido por um estudante: "tem tanta coisa pra gente estudar, porque os mesmos só pedem futebol? Não será futebol agora" (EPISÓDIO 18 -06/06/2016).

Essas passagens nos dizem muito acerca das sementes plantadas pelo currículo cultural da Educação Física. As posturas adotadas, por mais simples que possam parecer, revelam a produção de novos significados acerca do componente. Os estudantes demonstram que o currículo cultural da Educação Física atua para que certezas, antes intocadas, sejam desestabilizadas e desconstruídas. Confirmando os dizeres de Neira (2018), constata-se que a Educação Física cultural proporciona uma experiência ímpar de formação e engajamento político em busca da construção de uma sociedade menos desigual, mais democrática e equitativa. 


\section{CONSIDERAÇÕES FINAIS}

A análise dos materiais produzidos durante o trabalho de campo não deixa dúvidas que as crianças e jovens que participaram do estudo foram tocadas pelas aulas de Educação Física culturalmente orientadas, cumprindo com suas premissas em relação aos seus campos teóricos de inspiração, chegando a extrapolar as expectativas. Os episódios observados indicam que a proposta provoca sentimentos de inquietação nos estudantes. É justamente quando eles se sentem instigados a questionar 'porque isso é desse jeito? ou 'porque não podemos fazer de outra forma?' que ela mostra a que veio.

Com relação às significações produzidas pelos estudantes, as análises sugerem que o currículo cultural da Educação Física, de uma maneira geral, realiza bem a tarefa a que se propõe em auxiliar os alunos a compreenderem as práticas corporais e desconstruir os discursos que as cercam e as formam. O diálogo foi algo que se destacou na ação cotidiana da Educação Física cultural. Foi por meio dele que temas foram selecionados e situações didáticas readequadas sempre que necessário.

Notamos que a escolha e elaboração das atividades de ensino influenciaram nas significações das crianças e jovens sobre a proposta. Assistir vídeos, ler textos e imagens, observar e debater as explicações, vivenciar as práticas corporais e participar das desconstruções, ocasionaram a ampliação, o aprofundamento e a ressignificação dos saberes que os estudantes acessaram na escola ou fora dela.

É fácil perceber que os estudantes ampliam, aprofundam e ressignificam os conhecimentos referentes às práticas corporais tematizadas, sendo encorajados a desconstruir os discursos preconceituosos postos em circulação sobre as manifestações e seus representantes. Também apreciam o fato de que as aulas de Educação Física culturalmente orientadas não se restringem às vivências motoras das práticas corporais, dado que operam como dispositivos de estímulo à leitura e produção das brincadeiras, danças, lutas, esportes e ginásticas.

Por fim, esperamos que esse trabalho alimente o debate em torno do currículo cultural da Educação Física entre os professores e pesquisadores interessados na temática. Se o que se pretende é a construção de uma vida melhor para todas as pessoas, os resultados aqui apresentados indicam a potência que a proposta possui ao reconhecer e valorizar aqueles que a experimentam cotidianamente.

\section{REFERÊNCIAS BIBLIOGRÁFICAS}

Bonetto P. X. R. A "escrita-currículo" da perspectiva cultural da educação física: entre aproximações, diferenciações, laissez-faire e fórmula. Dissertação (Mestrado em Educação) - Faculdade de Educação. Universidade de São Paulo. São Paulo, 2016.

Corazza, S. M. O que quer um currículo? Pesquisas pós-críticas em educação. Petrópolis: Vozes, 2001.

Costa M. V. Poder, discurso e política cultural: contribuições dos Estudos Culturais ao campo do currículo. In: Lopes A. C., Macedo E. (Orgs.). Currículo: debates contemporâneos. São Paulo: Cortez, 2010. p. 133-149.

Escudero N. T. G. Avaliação da aprendizagem em educação física na perspectiva cultural: uma escrita autopoiética. Dissertação (Mestrado em Educação)-Faculdade de Educação. Universidade de São Paulo. São Paulo, 2011.

Klein C., Damico J. O uso da etnografia pós-moderna para a investigação de políticas públicas de inclusão social. In: Meyer D. E., Paraiso M. A. (Org.). Metodologias de pesquisas pós-críticas em educação. 2a ed. Belo Horizonte: Mazza, 2014. p. 65-87.

Mazzoni, A. V. "Eu vim do mesmo lugar que eles": relações entre experiências pessoais e uma Educação Física multiculturalmente orientada. 2013. 182 f. Dissertação (Mestrado em Educação) - Universidade de São Paulo, Faculdade de Educação, 2013.

Meyer D. E., Paraiso M. A. (Orgs.). Metodologias de pesquisas pós-críticas em educação. 2a ed. Belo Horizonte: Mazza, 2014.

Müller A. Avaliação no currículo cultural da Educação Física: o papel do registro na reorientação das rotas. Dissertação (Mestrado em Educação) - Faculdade de Educação. Universidade de São Paulo. São Paulo, 2016.

Neira M. G. Educação Física. São Paulo: Blucher, 2011.

Neira M. G.O currículo de Educação Física e o posicionamento dos sujeitos. Revista Contemporânea de Educação, Rio de Janeiro, v. 11, n. 22, p. 115-131, ago/dez, 2016a.

Neira M. G.Os procedimentos didáticos do currículo cultural da Educação Física. In: Neira M. G., Nunes M. L. F. (Orgs.). Educação Física cultural: escritas sobre a prática. Curitiba: CRV, 2016b. p. 17-50.

Neira M. G. Educação física cultural: inspiração e prática pedagógica. Jundiaí: Paco, 2018.

Neira M. G., Nunes M. L. F. As possibilidades de emergência do currículo cultural da Educação Física: contribuições do Grupo de Pesquisas em Educação Física escolar da FEUSP (GPEF). In: Maldonado D. T., Nogueira V. A., Farias U. S. (Orgs.). Os professores como intelectuais: novas perspectivas didático-pedagógicas na Educação Física Brasileira. Curitiba: CRV, 2018. p. 281-300.

Nelson C, Treichler P, Grossberg L. Estudos Culturais: uma introdução. In: Silva, T. T.(Org.). Alienígenas na sala de aula: uma introdução aos estudos culturais em educação. 8aed. Rio de Janeiro: Vozes, 2009. p. 7-38.

Neves M. R. O currículo cultural de Educação Física em ação: efeitos nas representações culturais dos estudantes sobre as práticas corporais e seus representantes. 2018. 198 f. Dissertação (Mestrado em Educação) Faculdade de Educação, Universidade de São Paulo, São Paulo, 2018 
Nunes H. C. B. O jogo da identidade e diferença no currículo cultural da Educação Física. Tese (Doutorado em Educação) - Faculdade de Educação, Universidade de São Paulo, São Paulo, 2018.

Oliveira Junior J. L., Neira M. G. O currículo cultural da Educação Física: entre as teorias críticas e pós-críticas. In: PONTES JUNIOR, José Airton de Freitas (Org.). Conhecimentos do professor de educação física escolar. Fortaleza: EdUECE, 2017. p. 13-63.

Paraiso M. A. Pesquisas pós-críticas em educação no Brasil: esboço de um mapa. Cadernos de Pesquisa, São Paulo, v. 34, n. 122, p. 283-303, maio/ago. 2004.

Salomão A. F. Pesquisas etnográficas em educação física escolar: um balanço de dissertações e teses. Tese (Doutorado em Educação) - Faculdade de Educação. Universidade de São Paulo. São Paulo, 2017.
Santos I. L. A tematização e a problematização no currículo cultural da Educação Física. Tese (Doutorado em Educação) - Faculdade de Educação. Universidade de São Paulo. São Paulo: FEUSP, 2016.

Silva T. T. O currículo como fetiche: a poética e a política do texto curricular. Belo Horizonte: Autêntica, 2010.

Silva T. T. Documentos de identidade: uma introdução às teorias do currículo. 3a ed. Belo Horizonte: Autêntica, 2011.

Silva T. T. A produção social da identidade e da diferença. In: Silva T. T. (Org.). Identidade e diferença: a perspectiva dos Estudos Culturais. 13a ed. Petrópolis: Vozes, 2013. p. 73-102.

Wortmann M. L. C. Análises culturais - um modo de lidar com histórias que interessam à educação. In: Costa, M. V. (Org.). Caminhos investigativos II: outros modos de pensar e fazer pesquisa em educação. Rio de Janeiro: Lamparina, 2002. p. 71-90. 